Ueb. die d. Geschlecht best. Ursachen u. d. Geschlechtsverhältn. d. Frösche. 13

\title{
Ueber die das Geschlecht bestimmenden Ursachen und die Geschlechtsverhältnisse der Frösche.
}

Von

E. PAnüger.

Zunächst muss ich die Geduld des Lesers in Anspruch nehmen, um die Resultate kennen zu lernen, welche die Aquarien I $\alpha$, III $\alpha, \operatorname{IV} \alpha, \mathrm{V} \alpha$ sowie I $\beta, \operatorname{III} \beta, \operatorname{IV} \beta, \mathrm{V} \beta$ lieferten. Die mit $\alpha$ bezeichneten enthalten Quappen, welche concentrirtem Samen, die mit $\beta$ bezeichneten solche, welche verdünntem Samen ihren Ursprung verdanken. Die Art der Ausfiihrung der Versuche war im Wesentlichen genau so wie im vorigen Aufsatze bereits für die Aquarien II $\alpha$ und II $\beta$ beschrieben worden ist.

\section{Geschichte der Aquarien $\mathrm{I} \alpha$ und $\mathrm{I} \beta$.}

Es handelt sich bei diesen Versuchen um "trockene" Befruchtung, wenn die Eier in concentrirten, das heisst also nicht mit Wasser vermischten Samen versenkt wurden. Die angewandten Thiere entstammen einer am 1. April 1882 ans Utrecht eingetroffenen Sendung brünstiger Froschpaare. Die künstliche Befruchtung geschah am 2. April mit Benutzung von 9 brünstigen Paaren, welche also 18 Einzelversuche lieferten. Da die Thiere meist wenig Samen in den Blasen hatten, liess ich die Uhrgläser nass, wie sie nach dem Abspülen bleiben. Der Versuch ist also gleichsam als halbtrockene Befruchtung in dem Falle anzusehen, wo die Eier in "concentrirtem" Samen gebadet wurden. Die Eier blieben nach der Befruchtung in den Uhrgläsern, welche in mit Wasser gefilltten Glasschalen stehen (provisorisehe Aquarien). Es wurde, da Abzählen der Eier sich als unthunlich erwies, zu entsprechenden Versuchen nach Augenmaass immer ungefähr gleiche Eizahl gewählt. Wegen der spärlichen Samenmenge in den Blasen musste ich zweimal die Hoden zerkleinern. Die Temperatur des Wassers, in 
welches die Eier kamen, war $11^{\circ}$ C. Die Befruchtungsversuche dauerten von 9 bis 1 Uhr Morgens. Nachmittags 5 Ubr hatten die um $10 \mathrm{Uhr}$ befruchteten Eier die erste Furchung vollzogen. Die um 1 Uhr befruchteten zeigten einen Theil der ersten Furche. Am 4. April waren die Eier bis zum Stadium der sogenannten Sandsteinformation des Dotters vorgeschritten. Nachdem die Larven ansgeschliupft und ihre Kiemen verloren, wurden alle Individuen der einzelnen Aquarien, sowie die Zahl der nicht angegangenen resp. abgestorbenen Eier gezählt. Die provisorischen Aquarien mit ungerader Zahl entsprachen immer den Versuchen mit concentrirtem Sperma, die mit gerader Zahl den Versuchen mit verdünntem Sperma. Durch einen Ungliicksfall verlor ich Aquarium 7 und 15; folglich war auch 8 und 16 verloren, da 8 mit 7 und 16 mit 15 correspondirt.

Zuächst zur Abzählung gelangten demnach die Aquarien: 1 und 2,3 und 4,5 und 6,9 und 10,11 und 12,13 and 14,17 und 18 . Das am 22. April 1882 erhaltene Resultat ergibt folgende Tabelle:

\begin{tabular}{|c|c|c|c|c|c|c|}
\hline $\begin{array}{c}\text { Nummer } \\
\text { des } \\
\text { provisori- } \\
\text { schen } \\
\text { Aqua- } \\
\text { riums. }\end{array}$ & $\begin{array}{l}\text { Gesammt- } \\
\text { zahl } \\
\text { der lebenden } \\
\text { Larven. }\end{array}$ & $\begin{array}{c}\text { Zahl } \\
\text { der ver- } \\
\text { dorbenen } \\
\text { Eier. }\end{array}$ & $\left|\begin{array}{c}\text { Nummer } \\
\text { des } \\
\text { provisori- } \\
\text { schen } \\
\text { Aqua- } \\
\text { riums. }\end{array}\right|$ & $\begin{array}{c}\text { Gesammt- } \\
\text { zahl } \\
\text { der lebenden } \\
\text { Larven. }\end{array}$ & $\begin{array}{c}\text { Zahl } \\
\text { der ver- } \\
\text { dorbenen } \\
\text { Eier. }\end{array}$ & $\begin{array}{c}\text { Zahl der } \\
\text { in die ent- } \\
\text { sprechenden } \\
\text { Aquarien } \\
\text { I } \alpha \text { und I } \beta \\
\text { ausgesetzten } \\
\text { Larven, je: }\end{array}$ \\
\hline $\begin{array}{r}1 \\
3 \\
5 \\
9 \\
11 \\
13 \\
17\end{array}$ & $\begin{array}{l}30 \\
68 \\
55 \\
45 \\
67 \\
69 \\
58\end{array}$ & $\begin{array}{l}0 \\
0 \\
2 \\
8 \\
0 \\
4 \\
1\end{array}$ & $\begin{array}{r}2 \\
4 \\
6 \\
10 \\
12 \\
14 \\
18\end{array}$ & $\begin{array}{l}30 \\
61 \\
83 \\
53 \\
98 \\
69 \\
73\end{array}$ & $\begin{array}{l}0 \\
0 \\
5 \\
9 \\
2 \\
2 \\
4\end{array}$ & $\begin{array}{l}30 \\
61 \\
55 \\
45 \\
67 \\
69 \\
58\end{array}$ \\
\hline & 392 & 15 & & 467 & 22 & 385 \\
\hline
\end{tabular}

Hieraus folgt, dass $392+15=407$ mit concentrirtem Samen befruchtete Eier lieferten 392 kräftige Larven. Mortalität 3,7\%. Ferner $467+22$ mit verdünntem Samen befruchtete Eier lieferten 467 kräftige Larven. Mortalität 4,5\% \% Hier sind natïrlich anch einbegriffen die Eier, welche sich gar nicht entwickelt haben. 
Ueb. die d. Geschlecht best. Ursachen u. d. Geschlechtsverhältn. d. Frösche. 15

Am 22. April wurden nun von diesen Larven 385 Stück in das definitive Thonaquarium I $\alpha$ und ebenso 385 Stück in I $\beta$ ausgesetzt. Die mit $\alpha$ bezeichneten Thonaquarien entsprechen dem concentrirten, die mit $\beta$ bezeichneten dem verdünnten Sperma. Das Wasser der Thonaquarien hatte beim Aussetzen $16^{\circ} \mathrm{C}$.

Am 5. April erhielt ich eine zweite Froschsendung aus Utrecht und gewann unter anderen noch folgende provisorische Aquarienpaare 69 und 70 und 77 und 78 , denen die folgende Tabelle entspricht:

\begin{tabular}{|c|c|c|c|c|c|c|}
\hline $\begin{array}{c}\text { Nummer } \\
\text { des } \\
\text { provisori- } \\
\text { schen } \\
\text { Aqua- } \\
\text { riums. }\end{array}$ & $\begin{array}{c}\text { Gesammt- } \\
\text { zahl } \\
\text { der lebenden } \\
\text { Larven. }\end{array}$ & $\begin{array}{c}\text { Zahl } \\
\text { der ver- } \\
\text { dorbenen } \\
\text { Eier. }\end{array}$ & $\mid \begin{array}{c}\text { Nummer } \\
\text { des } \\
\text { provisori- } \\
\text { schen } \\
\text { Aqua- } \\
\text { riums. }\end{array}$ & $\begin{array}{c}\text { Gesammt- } \\
\text { zahl } \\
\text { der lebenden } \\
\text { Larven. }\end{array}$ & $\begin{array}{c}\text { Zahl } \\
\text { der ver- } \\
\text { dorbenen } \\
\text { Eier. }\end{array}$ & $\begin{array}{l}\text { Zahl der } \\
\text { in die ent- } \\
\text { sprechenden } \\
\text { Aquarien } \\
\text { I } \alpha \text { und I } \beta \\
\text { ausgesetzten } \\
\text { Larven, je: }\end{array}$ \\
\hline $\begin{array}{l}69 \\
77\end{array}$ & $\begin{array}{r}61 \\
126\end{array}$ & $\begin{array}{l}12 \\
12\end{array}$ & $\begin{array}{l}70 \\
78\end{array}$ & $\begin{array}{r}80 \\
136\end{array}$ & $\begin{array}{l}17 \\
10\end{array}$ & $\begin{array}{r}61 \\
126\end{array}$ \\
\hline & 187 & 24 & & 216 & 27 & 187 \\
\hline
\end{tabular}

Demnach ist die Mortalität in den dem concentrirten Sperma entsprechenden Versuchen $=11,4 \%$, in den dem verdïnnten entsprechenden $=11,1 \%$.

In die definitiven Aquarien $\mathrm{I} \alpha$ und $\mathrm{I} \beta$ wurden diese 187 Larven am 26. April ausgesetzt. Die Summe derselben ist demnach je $385+187=572$.

Diese je 572 Larven sind die Früchte von 9 Froschpaaren. Die ersten vierfüssigen Larven wurden am 6 . Juni in Aquarium $\mathrm{I} \beta$ bemerkt, am 8 . Juni ziemlich viele. In I $\alpha$ erschienen die ersten vierfüssigen Larven einige Tage später. Da nun die Resorption des Schwanzes nur ein paar Tage in Anspruch nimmt, so hatte die ganze Entwicklung vom $\mathrm{Ei}$ bis zum definitiven Thiere nur zwei Monate in Anspruch genommen. Weil eine am 29. Juni vorgenommene Untersuchung ergab, dass für die Diagnose des Geschlechts von 9 Individuen vier Mal das Mikroskop herangezogen werden musste, fing ich erst am 7. Juli, 8. Juli, 11. Juli, 13. Juli 
die sämmtlichen Fröschchen allmählig aus dem Grase der Aquarien I $\alpha$ und I $\beta$ und bestimmte mit Lupe, eventuell anch Mikroskop, ob es sich um einen Hoden oder Eierstock handelte.

Aus Aquarium $\mathrm{I} \alpha$, in welches 572 Larven eingesetzt worden waren, konnte ich 400 junge Frösche sammeln, so dass die Mortalität $30,1 \%$ betrug. Selbstverständlich steht hier der ganze Verlust, von dem aber ein nicht geringer Theil durch die Feinde im Wasser und im Grase (besonders Raubkäfer), und nicht durch eigentliche Krankheit bedingt ist. Bei diesen 400 jungen Fröschchen wurde 49 mal Hode, 351 mal Eierstock diagnostirt.

Aus Aquarium I $\beta$, welches ich gleichzeitig mit Aquarium I $\alpha$ entleerte, gewann ich von den eingesetzten 572 Larven 380 junge Fröschchen, bei denen 53 mal Hode und 324 mal Eierstock diagnostirt wurde. Mortalität $33,5 \%$.

Das Resultat erhellt übersichtlich aus folgender Tabelle:

\begin{tabular}{|c|c|c|c|c|}
\hline $\begin{array}{l}\text { Nummer } \\
\text { der } \\
\text { Aquarien. }\end{array}$ & $\begin{array}{c}\text { Mortalität } \\
\text { in } \% .\end{array}$ & $\begin{array}{c}\% \text {-Gehalt } \\
\text { Hode. }\end{array}$ & $\begin{array}{l}\% \text {-Gehalt. } \\
\text { Eierstock. }\end{array}$ & $\begin{array}{l}\text { Gesammt- } \\
\text { zahl der } \\
\text { untersuchten } \\
\text { Fröschchen. }\end{array}$ \\
\hline $\mathrm{I} \alpha$ & 30,1 & 12,2 & 87,8 & 400 \\
\hline $\mathrm{I} \beta$ & 33,5 & 14,1 & 85,9 & 380 \\
\hline
\end{tabular}

Der Procentgehalt an Männchen betrug also sogar weniger in den dem concentrirten Sperma entsprechenden Versuchen: 12,2 und 14,1 bei den dem verdïnnten entsprechenden.

Die genanere Discussion der Resultate dieser und der folgenden Aquarien wird später folgen.

\section{Geschichte der Aquarien III $\alpha$ nnd III $\beta$.}

Am 5. April erhielt ich eine zweite Sendung brünstiger Froschpaare aus Utreeht und benutzte dieselben unter anderen zur Bevölkerung der Aquarien 51 bis 64 durch Befruchtungsversuehe, die absolut identisch mit denen ausgefiilht wurden, welche ich bei Aquarium II $\alpha$ und II $\beta$ beschrieben habe. Theilweise sind, was 
Ueb. die d. Geschlecht best. Ursachen u. d. Geschlechtsverhältn. d. Frösche. 17

nicht ganz unwichtig, diese zu III $\alpha$ und III $\beta$ gehörigen Versuche an demselben Tage, wie die zu II $\alpha$ und II $\beta$ gehörigen, und alle von meiner Hand ausgefuhht, die alle Manipulationen vollzog.

Das am 26. April constatirte Resultat der provisorischen Aquarien war :

\begin{tabular}{|c|c|c|c|c|c|c|}
\hline $\begin{array}{c}\text { Nummer } \\
\text { des } \\
\text { provisori- } \\
\text { schen } \\
\text { Aqua- } \\
\text { riums. }\end{array}$ & $\begin{array}{c}\text { Gesammt- } \\
\text { zahl } \\
\text { der lebenden } \\
\text { Larven. }\end{array}$ & $\begin{array}{c}\text { Zahl } \\
\text { der ver- } \\
\text { dorbenen } \\
\text { Eier. }\end{array}$ & $\begin{array}{c}\text { Nummer } \\
\text { des } \\
\text { provisori- } \\
\text { schen } \\
\text { Aqua- } \\
\text { riums. }\end{array}$ & $\begin{array}{c}\text { Gesammt- } \\
\text { zahl } \\
\text { der lebenden } \\
\text { Larven. }\end{array}$ & $\begin{array}{c}\text { Zahl } \\
\text { der ver- } \\
\text { dorbenen } \\
\text { Eier. }\end{array}$ & $\begin{array}{l}\text { Zahl der } \\
\text { in die Thon- } \\
\text { aquarien } \\
\text { III u. III } \beta \\
\text { ausgesetzten } \\
\text { Larven, je: }\end{array}$ \\
\hline $\begin{array}{l}51 \\
53 \\
55 \\
59 \\
61\end{array}$ & $\begin{array}{l}56 \\
57 \\
42 \\
17 \\
38\end{array}$ & $\begin{array}{r}1 \\
0 \\
0 \\
10 \\
3\end{array}$ & $\begin{array}{l}52 \\
54 \\
56 \\
60 \\
62\end{array}$ & $\begin{array}{l}56 \\
90 \\
42 \\
17 \\
52\end{array}$ & $\begin{array}{l}5 \\
0 \\
0 \\
8 \\
2\end{array}$ & $\begin{array}{l}56 \\
57 \\
42 \\
17 \\
38\end{array}$ \\
\hline & 210 & 14 & & 257 & 15 & 210 \\
\hline
\end{tabular}

Mortalität für die dem concentrirten Sperma entsprechenden Versuche $=6,2 \%$, für die anderen $5,2 \%$.

Zu diesem Versuche möge die Bemerkung hinzugefügt werden, dass die Aquarien 57 und 58 deshalb in der Reihe fehlen, weil die mit diesen Zahlen bezeichneten Aquarien vor dem Versuch zerbrachen. Die Aquarien 63 und 64 fehlen, weil diese zu nahe am geöffneten Fenster standen und die Quappen in einer Aprilnacht durch Frost getödtet wurden.

Die erhaltenen je 210 Larven setzte ich am 26. April in Aquarium III $\alpha$ und III $\beta$.

In diese Aquarien brachte ich ausserdem noch Larven von Schweizer Fröschen aus Glarus. Ish erhielt aus einem hoch gelegenen Gebirgsee durch die guitige Vermittelung des verehrten Collegen Luchsinger am 19. April viele brünstige Paare. Ein Theil derselben wurde $z$ Versuchen derselben Art angewandt, wie die bisher beschriebenen, $d$. h. die Befruchtung ganz trocken ausgefuihrt, wenn die Eier in concentrirtes Sperma versenkt werden sollten.

Die Befruchtung geschah am 21. April und das Resultat, welches die provisorischen Aquarien, die für die definitiven III $\alpha$ und III $\beta$ bestimmt waren, ergaben, ersieht man aus folgender Tabelle : 


\begin{tabular}{|c|c|c|c|c|c|c|}
\hline $\begin{array}{c}\text { Nummer } \\
\text { der } \\
\text { provisori- } \\
\text { schen } \\
\text { Aqua- } \\
\text { rien. }\end{array}$ & $\begin{array}{c}\text { Gesammit- } \\
\text { zahl } \\
\text { der lebenden } \\
\text { Larven. }\end{array}$ & $\begin{array}{c}\text { Zahl } \\
\text { der ver- } \\
\text { dorbenen } \\
\text { Eier. }\end{array}$ & $\begin{array}{c}\text { Nummer } \\
\text { der } \\
\text { provisori- } \\
\text { schen } \\
\text { Aqua- } \\
\text { rien. }\end{array}$ & $\begin{array}{l}\text { Gesammt- } \\
\text { zahl } \\
\text { der lebenden } \\
\text { Larven. }\end{array}$ & $\begin{array}{c}\text { Zahl } \\
\text { der ver= } \\
\text { dorbenen } \\
\text { Eier. }\end{array}$ & $\begin{array}{c}\text { Zahl der } \\
\text { in die Thon- } \\
\text { aquarien } \\
\text { IIl } \alpha \text { u. III } \beta \\
\text { ausgesetzten } \\
\text { Larven, je: }\end{array}$ \\
\hline $\begin{array}{r}90 \\
101 \\
103 \\
105\end{array}$ & $\begin{array}{r}57 \\
80 \\
99 \\
268\end{array}$ & $\begin{array}{l}1 \\
2 \\
0 \\
0\end{array}$ & $\begin{array}{l}100 \\
102 \\
104 \\
106\end{array}$ & $\begin{array}{l}121 \\
116 \\
147 \\
165\end{array}$ & $\begin{array}{l}1 \\
2 \\
7 \\
0\end{array}$ & $\begin{array}{r}57 \\
80 \\
99 \\
165\end{array}$ \\
\hline & 504 & 3 & & 549 & 10 & 401 \\
\hline
\end{tabular}

Mortalität der dem concentrirten Sperma entsprechenden Aquarien $=0,6 \%$, die der anderen $1,8 \%$.

Diese je 401 Individuen wurden am 6. Mai noch za den 210 bereits darin befindlichen gebracht. Ursprünglich enthielten die Aquarien III also je 610 Individuen.

Am 11. Juni entnahm ich aus III $\alpha 22$ junge Fröschchen, deren Geschlecht sich nicht sicher bestimmen liess. Am 29. Juni wurde ein Todter, am 2. Juli 11 Todte gefunden und demnach am 3. Juli wegen eines in diesem Aquarium acut auftretenden Sterbens sofort alle gefangen und entsprechend ebenso bei III $\beta$ verfahren.

Das Resultat gibt folgende Tabelle:

\begin{tabular}{|c|c|c|c|c|c|c|c|}
\hline \multirow{2}{*}{$\begin{array}{c}\text { Zahl } \\
\text { der in die } \\
\text { Aquarien } \\
\text { gesetzten } \\
\text { Quappen. }\end{array}$} & \multirow{2}{*}{$\begin{array}{c}\text { Zahl } \\
\text { der er- } \\
\text { haltenen } \\
\text { Frösch- } \\
\text { chen. }\end{array}$} & \multicolumn{2}{|c|}{ Hode } & \multicolumn{2}{|c|}{ Eierstock. } & \multirow{2}{*}{$\begin{array}{l}\text { Mor- } \\
\text { talität. }\end{array}$} & \multirow{2}{*}{ 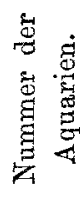 } \\
\hline & & $\begin{array}{l}\text { Zahl der } \\
\text { Thiere. }\end{array}$ & $\begin{array}{c}\% \\
\text { Gehalt. }\end{array}$ & $\begin{array}{l}\text { Zahl der } \\
\text { Thiere. }\end{array}$ & $\begin{array}{c}\% \\
\text { Gehalt. }\end{array}$ & & \\
\hline 611 & 226 & 47 & 20,8 & 179 & 79,2 & 63,0 & $\operatorname{III} \alpha$ \\
\hline 611 & 380 & 73 & 19,0 & 308 & 81,0 & 37,3 & $\operatorname{III} \beta$ \\
\hline
\end{tabular}

Der Procentgehalt der Männchen ist diesmal bei den dem concentrirten Sperma entsprechenden Versuchen etwas höher: 20,8, in den dem verdünnten entsprechenden 19,0. 
Ueb. die d. Geschlecht best. Ursachen u. đ. Geschlechtsverhältn. d. Frösche. 19

\section{Geschichte der Aquarien IV $\alpha$ und IV $\beta$.}

Die grossen Aquarien IV $\alpha$ und IV $\beta$ sollten alle Versuchspaare aufnehmen, bei denen der verdünnte Samen so wenig Spermatozoen enthielt, dass nur ein Theil der Eier befruchtet wurde. Diese Versuchspaare las ich mit grösster Sorgfalt aus allen Aquarien aus, wo der Zufall eine Minimalbefruchtung zu Stande gebracht hatte. Sie wird daran erkannt, dass dieselben Eier (d. h. aus demselben Uterus), welche mit concentrirtem Sperma befruchtet, sich alle oder fast alle entwickelt hatten, sich im Gegentheil nur zum kleinen Theile belebten, wenn sie mit hinreichend verdünntem Samen behandelt worden waren. Ein wesentliches Kennzeichen der Minimal-Befruchtung ist, dass die nicht angegangenen Eier auch auf der Oberfläche des Laichs liegen. Denn ein Ei, welches unter einem anderen sich befindet, verdirbt sehr oft und hieraus ist also nicht auf mangelnde Befruchtung zu schliessen. Der concentrirte Same war bei diesen Versuchen bald ohne, bald mit Zusatz einer kleinen Wassermenge verwandt worden.

$\mathrm{Zu}$ diesen Versuchen dienten also zunächst Aquarien, die mit Eiern aus Glarus besetzt worden waren. Die Tabelle ergibt den Erfolg der Züchtung in den provisorischen Glasaquarien, die am 6. Mai von mir ausgezählt wurden :

\begin{tabular}{|c|c|c|c|c|c|}
\hline \multicolumn{3}{|c|}{$\begin{array}{l}\text { Aquarien, dem concentrirten } \\
\text { Samen entsprechend: }\end{array}$} & \multicolumn{3}{|c|}{$\begin{array}{l}\text { Aquarien, der Minimum-Befruchtung } \\
\text { entsprechend: }\end{array}$} \\
\hline $\begin{array}{c}\text { Nummer } \\
\text { des } \\
\text { Aquariums. }\end{array}$ & $\begin{array}{c}\text { Zahl der } \\
\text { verdorbenen } \\
\text { Eier. }\end{array}$ & $\begin{array}{c}\text { Zahl der } \\
\text { gezüchteten } \\
\text { Quappen. }\end{array}$ & $\begin{array}{c}\text { Nummer } \\
\text { des } \\
\text { Aquariums. }\end{array}$ & $\begin{array}{c}\text { Zahl der } \\
\text { verdorbenen } \\
\text { Eier. }\end{array}$ & $\begin{array}{c}\text { Zahl der } \\
\text { gezüchteten } \\
\text { Quappen. }\end{array}$ \\
\hline $\begin{array}{r}89 \\
121\end{array}$ & $\begin{array}{r}12 \\
4\end{array}$ & $\begin{array}{r}98 \\
104\end{array}$ & $\begin{array}{r}90 \\
122\end{array}$ & über $\begin{array}{r}100 \\
60\end{array}$ & $\begin{array}{l}21 \\
44\end{array}$ \\
\hline
\end{tabular}

Es wurden also aus diesen Aquarien einmal je 21 und dann je 44, also je 65 Quappen in die grossen Thonaquarien IV $\alpha$ und IV $\beta$ am 6. Mai ausgesetzt; wie immer erhält $\alpha$ die Quappen, welche dem concentrirten Samen, $\beta$ die, welche dem verdiunten ihren Ursprung verdanken. 
Am 26. April hatte ich bereits einige Minimumversuche ausgezählt, die von Königsberger Froschpaaren stammten. Folgende Tabelle gibt wieder das Resultat:

\begin{tabular}{c||c|c||c|c}
\hline \multicolumn{2}{c|}{$\begin{array}{c}\text { Aquarien, dem concentrirten } \\
\text { Samen entsprechend: }\end{array}$} & Aquarien, der Minimum-Befruchtung: \\
entsprechend:
\end{tabular}

Es wurden also aus den Aquarien 45 und 46 je 51 Quappen, aus den Aquarien 47 und 48 je 22 Quappen, aus den Aquarien 49 und 50 je 11 Quappen in die grossen Thonaquarien IV $\alpha$ und IV $\beta$ eingesetzt, in toto also von den Königsberger Quappen je 84 Stïck.

Hierza kommt noch ein Paar provisorischer Aquarien, die mit den Früchten von Utrechter Fröschen bevölkert waren. Ich zählte diese aus am 1. Mai:

\begin{tabular}{|c|c|c|c|c|c|}
\hline \multicolumn{3}{|c|}{$\begin{array}{l}\text { Aquarium, dem concentrirten } \\
\text { Sperma entsprechend: }\end{array}$} & \multicolumn{3}{|c|}{$\begin{array}{l}\text { Aquarium, der Minimalbefruchtung } \\
\text { entsprechend: }\end{array}$} \\
\hline $\begin{array}{c}\text { Nummer } \\
\text { des } \\
\text { Aquariums. }\end{array}$ & $\mid \begin{array}{c}\text { Zahl der } \\
\text { verdorbenen } \\
\text { Eier. }\end{array}$ & $\begin{array}{c}\text { Zahl der } \\
\text { gezüchteten } \\
\text { Quappen. }\end{array}$ & $\begin{array}{c}\text { Nummer } \\
\text { des } \\
\text { Aquariums. }\end{array}$ & $\begin{array}{c}\text { Zahl der } \\
\text { verdorbenen } \\
\text { Eier. }\end{array}$ & $\begin{array}{c}\text { Zahl der } \\
\text { gezüchteten } \\
\text { Quappen. }\end{array}$ \\
\hline 73 & $?$ & 145 & 74 & circa 30 & 145 \\
\hline
\end{tabular}

Je 145 Utrechter Quappen kamen also auch noch in die grossen Thonaquarien IV $\alpha$ und IV $\beta$, demnach in Summa je 294 Stuiek.

Aus den Aquarien IV $\alpha$ und IV $\beta$ wurden die jungen Fröschchen von mir gefangen am 1. Juli, 2. Juli, 7. Juli, 10. Juli, 12. Juli und von mir bestimmt. Schon am 11. Juni hatte ich aus IV $\beta 35$ Stück kleine schöne Fröschschen ohne Schwanz entnommen; die Diagnose war unsicher: deshalb figurirt in den Tabellen eine viel 
Ueb. die d. Geschlecht best. Ursachen u. d. Geschlechtsverhältn. d. Frösche. 21

grössere Zahl gezüchteter Fröschchen, als für die Geschlechtsbestimmung verwerthet worden sind.

Resultat:

\begin{tabular}{|c|c|c|c|c|c|c|c|}
\hline \multirow{2}{*}{$\begin{array}{c}\text { Zahl } \\
\text { der in die } \\
\text { Aquarien } \\
\text { gesetzten } \\
\text { Quappen. }\end{array}$} & \multirow{2}{*}{$\begin{array}{c}\text { Zahl } \\
\text { der er- } \\
\text { haltenen } \\
\text { Frösch- } \\
\text { chen. }\end{array}$} & \multicolumn{2}{|c|}{ Hode } & \multicolumn{2}{|c|}{ Eierstock } & \multirow{2}{*}{$\begin{array}{l}\text { Mor- } \\
\text { talität. }\end{array}$} & \multirow{2}{*}{ 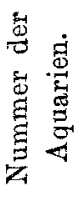 } \\
\hline & & $\begin{array}{c}\text { Zahl der } \\
\text { Indivi- } \\
\text { duen. }\end{array}$ & $\begin{array}{c}\% \\
\text { Gehalt. }\end{array}$ & $\begin{array}{l}\text { Zahl der } \\
\text { Indivi- } \\
\text { duen. }\end{array}$ & $\begin{array}{c}\% \\
\text { Gehalt. }\end{array}$ & & \\
\hline 294 & 177 & 49 & 27,8 & 127 & 72,6 & 39,8 & $\operatorname{IV} \alpha$ \\
\hline 294 & 151 & 29 & 25,0 & 87 & 75,0 & 48,6 & $\operatorname{IV} \beta$ \\
\hline
\end{tabular}

Geschichte der Aquarien $\mathrm{V} \alpha$ und $\mathrm{V} \beta$.

Diese grossen Aquarien wurden mit je 840 Quappen besetzt und sollten einen analogen Versuch zu IV $\alpha$ und IV $\beta$ bilden. Als die Tage im Mai plötzlich sehr heiss wurden, versehwanden diese Quappen im Schlamm und kamen nie wieder zum Vorschein. Aus Aquarium $V \alpha$ erhielt ich schliesslich von 840 Quappen nur 58 Fröschchen und aus $V \beta$ eirca 10.

Der Vollständigkeit halber gebe ich das Resultat von $\mathrm{V} \alpha$ da diese Fröschchen sämmtlich von Glaruspaaren stammen:

Resultat:

\begin{tabular}{|c|c|c|c|c|c|c|c|}
\hline \multirow{2}{*}{$\begin{array}{c}\text { Zahl } \\
\text { der in die } \\
\text { Aquarien } \\
\text { gesetzten } \\
\text { Quappen. }\end{array}$} & \multirow{2}{*}{$\begin{array}{c}\text { Zahl } \\
\text { der er- } \\
\text { haltenen } \\
\text { Frösch- } \\
\text { chen. }\end{array}$} & \multicolumn{2}{|c|}{ Hode } & \multicolumn{2}{|c|}{ Eierstock } & \multirow{2}{*}{$\begin{array}{l}\text { Mor- } \\
\text { talität. }\end{array}$} & \multirow{2}{*}{ 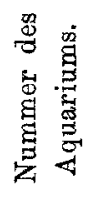 } \\
\hline & & $\| \begin{array}{c}\text { Zahl der } \\
\text { Indivi- } \\
\text { duen. }\end{array}$ & $\begin{array}{c}\% \\
\text { Gehalt. }\end{array}$ & $\begin{array}{c}\text { Zahl der } \\
\text { Indivi- } \\
\text { duen. }\end{array}$ & $\begin{array}{c}\% \\
\text { Gehalt. }\end{array}$ & & \\
\hline 840 & 58 & 13 & 22,4 & 45 & 77,6 & 93,1 & $\mathrm{~V} \alpha$ \\
\hline
\end{tabular}

Stellen wir nun in einer Generaltabelle die wesentlichen uns in diesem Aufsatze interessirenden Zahlen zusammen: 
Generaltabelle.

\begin{tabular}{|c|c|c|c|c|c|c|c|c|c|}
\hline $\begin{array}{l}\text { Zahl } \\
\text { der in die } \\
\text { Aquarien } \\
\text { gesetzten } \\
\text { Quappen. }\end{array}$ & 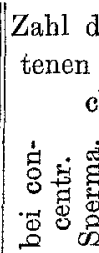 & 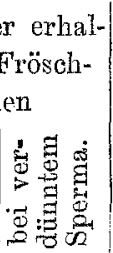 & $\begin{array}{c}\text { Zahl } \\
\text { der } \\
\delta \\
\text { bei c } \\
\text { tri } \\
\text { Spe }\end{array}$ & $\begin{array}{l}\% \% \text { Ge- } \\
\text { halt } \\
\text { an } \delta \\
\text { oncen- } \\
\text { tem } \\
\text { ma. }\end{array}$ & $\begin{array}{l}\text { Zahl } \\
\text { der } \\
\sigma \\
\text { bei } \\
\text { dün } \\
\text { Sp }\end{array}$ & $\begin{array}{l}0 \text { Ge- } \\
\text { halt } \\
\text { der } d \\
\text { ver- } \\
\text { tem } \\
\text { rma. }\end{array}$ & \multicolumn{2}{|c|}{ 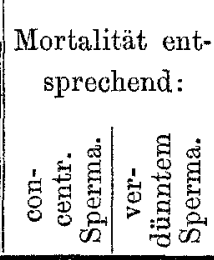 } & \multirow{2}{*}{ 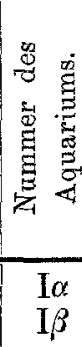 } \\
\hline $\begin{array}{l}572 \\
572\end{array}$ & 400 & $\overline{380}$ & 49 & 12,2 & $\overline{53}$ & $\overline{14,1}$ & $\stackrel{30,1}{-}$ & $\overline{33,5}$ & \\
\hline $\begin{array}{l}363 \\
363\end{array}$ & $\begin{array}{l}166 \\
-\end{array}$ & $\overline{204}$ & 80 & $\stackrel{48,4}{-}$ & $\overline{99}$ & $\overline{48,5}$ & 54,5 & $\overline{43,7}$ & $\begin{array}{l}\operatorname{II} \alpha \\
\mathrm{II} \beta\end{array}$ \\
\hline $\begin{array}{l}611 \\
611\end{array}$ & $\begin{array}{l}226 \\
-\end{array}$ & $\overline{380}$ & 47 & 20,8 & $\overline{73}$ & $\overline{19,0}$ & 63,0 & $\overline{37,3}$ & $\begin{array}{l}\operatorname{III} \alpha \\
\operatorname{III} \beta\end{array}$ \\
\hline $\begin{array}{l}294 \\
294\end{array}$ & 177 & $\overline{151}$ & $\stackrel{49}{-}$ & 27,8 & $\overline{29}$ & $\overline{25,0}$ & 39,8 & $\overline{48,6}$ & $\begin{array}{l}I V \alpha \\
I V \beta\end{array}$ \\
\hline \multicolumn{3}{|c|}{ Summe: } & \multicolumn{2}{|r|}{109,2} & \multicolumn{2}{|r|}{106,6} & & & \\
\hline \multicolumn{2}{|c|}{ Mittel: } & & & 27,3 & & 26,6 & & & \\
\hline
\end{tabular}

Der Procentgehalt an Männchen in den dem concentrirten Sperma entsprechenden Versuchen ist demnach $27,3 \%$, in dem dem verdünnten entsprechenden $26,6 \%$ - oder

die Concentration des Samens hat keinen Einfluss anf das Geschlecht.

Der Leser, welcher anfmerksam die Thatsachen verfolgt hat, wird gleich mir im höchsten Grade erstaunt gewesen sein, dass in den Aquarien $\mathrm{I} \alpha$ und $\mathrm{I} \beta$ die männlichen Individuen wie bei den bekannten Versuchen Born's fast versehwunden sind. Denn die Procentzahl beträgt nur 12,2 bis 14,1 d. h. im Mittel 13,1 . Bei Born war der Werth noch etwas kleiner: circa 5. Wir hatten im vorigen Jahre das fast vollständige Verschwinden des männlichen Geschlechtes durch die ungehenere Mortalität erklärt, die Born's Versuche schädigte.

Meine in diesem Jahre ausgefuhrten Versuche zeigen, dass zwischen der Mortalität und dem Geschlecht keine Beziehung existirt. Gerade der Versuch I $\alpha$, bei dem die Mortalität am kleinsten ist, liefert die Minimalzahl für das männliche Geschlecht. In dem Versuche II $\alpha$ und II $\beta$, der eine sehr grosse Mortalität aufweist, ergibt sich die höehste Procentzahl für das männliche Geschlecht. 
Ja obwohl Versuch II $\alpha$ und II $\beta$ eine ganz verschiedene Mortalität aufweisen, ist die Procentzahl für das männliche Geschlecht dieselbe, und dies ist darum sehr wichtig, weil die Thiere in II $\alpha$ und II $\beta$ absolute Geschwister sind.

Ferner aber findet sich, dass in dem Aquarium ( $\mathrm{V} \alpha$ ), wo die Mortalität ein Maximum von 93,1\% erreicht, der Procentgehalt an Männchen als ein mittlerer erscheint.

Auffallend ist ferner, dass auch die Aquarien III $\alpha, \operatorname{III} \beta, \operatorname{IV} \alpha$, IV $\beta, V \alpha$ und sicher auch $V \beta$, also alle Aquarien ausser zweien sehr niedrige Werthe für die Procentzahl der Männchen liefern. Ja nimmt man den hohen Werth von II $\alpha$ und II $\beta$ hinzu, und zieht dann für alle Versuche das Mittel, so erhält man doch einen sehr niedrigen Werth für den Procentgehalt der Männchen bei diesen durch künstliche Befruchtung entstandenen Thieren. Es erwächst der Verdacht, dass hier in geringerem Grad im Spiele ist derselbe Umstand, der bei den Verstuchen Born's das männliche Geschlecht batte fast ganz versehwinden lassen.

Absichtlich habe ich alle Versuche in jeder Beziehung ganz allein und olne Assistenz gemacht und alle Manipulationen mit eigener Hand vollzogen. An demselben Tage und auf dieselbe Weise befruchtete ich einen Theil der Eier, welche später in die Aquarien $\mathrm{I} \alpha$ und I $\beta, \Pi \alpha$ and II $\beta$ kamen. Ich konnte mich nicht entsinnen, dass ein irgend wesentlicher Untersehied in den bei der künstlichen Befruchtung ausgeführten Verrichtungen beobachtet worden sei.

Als ich das Aquarium I $\alpha$ zu untersuchen anfing und unter 30 Individuen, die ich zufällig nacheinander herausgriff, sich nicht ein einziges Männchen zeigte, drängte sich mir wieder der Gedanke auf, die Frösche seien doch Hermaphroditen, und ich sei so gliueklich gewesen, gerade die richtige Entwickelungsperiode zu treffen. Da ich aber dann zu derselben Zeit die Frösche aus Aqnarium II $\alpha$ und II $\beta$ untersuchte und bemerkte, dass beide Geschlechter fast ganz in gleicher Zahl vertreten waren, obwohl diese Fröschchen genau so alt wie die des Aquariums I und unter ganz denselben Bedingungen sich entwickelt hatten, musste jch jene Vermuthung wieder fallen lassen, fuir die ich auch im vorigen Jahre keinen thatsächlichen Anhalt finden konnte.

Indem ich uber das Räthsel nachdachte, fiel mir auf, dass das Resultat, welches die Aquarien III $\alpha$ III $\beta$, IV $\alpha$ und IV $\beta$ er- 
geben hatten, berechnet werden kounte aus den Resultaten von I $\alpha$, I $\beta$, II $\alpha$ und II $\beta$ and $\mathrm{V} \alpha$.

Man merke auf:

Aquarium III erhielt 210 Fröschchen, deren Eltern aus Utrecht, und 401 Fröschchen, deren Eltern aus Glarus waren. Das Aquarium 1, das nur Fröschehen mit Ursprung aus Utrecht enthielt, ergab 13,1\% für das männliche Geschlecht, und das Aquarium $V$, das nur Fröschchen mit Ursprung aus Glarus enthielt, lieferte 22,4\% Männchen.

Folglich mussten unter 210 jungen Utrechter Fröschchen 27,5 Männchen, unter 401 Glaruser 89,6 sein, in Summa 117. Also die 611 Insassen von Aquarium III mussten 117 Männehen liefern, d. h. 19,1\%. Beobachtet wurde in Aquarium III $\beta$ 19,0\%, in III $\alpha$ 20,8, im Mittel

$$
19,9 \% \text {. }
$$

Gehen wir zu Aquarium IV $a$ und IV $\beta$.

Dies enthielt:

1) 65 Frösche (Glarusabstammung) und da das Glarusaquarium V 22,6\% Männchen geliefert hatte, mussten diese 65 Frösche 15 Männchen aufweisen;

2) 145 Frösche (Utrechter Abstammung), folglich mit 19 Männchen;

3) 84 Frösche (Königsberger Abstammung), folglich mit 41 Männchen. Daraus als berechnete Summe aller Männchen des Aquarium IV 75. Wenn aber 294 (Gesammtzahl der Thiere in IV) 75 Männchen enthalten, so beträgt der Procentgehalt 25,5 für die Männchen. Gefunden ist in Aquarium IV $\beta$ 25,0, in Aquarium IV $\alpha$ 27,8 für das männliche Geschlecht.

Hieraus geht eine grosse Thatsache hervor, die nachher noch ganz fest begründet werden soll. Künstliche Befruchtung mit allen ihren abnormen Einwirkung en auf Ei und Same, Aenderung des Klima's, des Wassers, der Nahrung u. s. w. hat keinen Einfluss auf die relative Beziehung der beiden Geschlechter zu einander gehabt. Das Gesehlecht dieser jungen Frösche war schon bestimmt, ehe die Eier, aus denen sie entstanden, nach Bonn kamen, um hier befruchtet zu werden.

Es handelt sich jetzt um den strengen Beweis.

Durch die gütige Vermittelung meines verehrten Collegen Prof. Engelmann erbielt ich am 19. Juli aus Utrecht 459 Stick 
diesjähriger junger R. fuscae, die sich in der freien Natur entwickelt hatten, unter denen ich 60 Männchen fand oder $\mathbf{1 3 , 2} \%$, das heisst genau soviel als bei den in Bonn künstlich gezüchteten Thieren, deren Eltern aus Utrecht waren, von mir bestimmt worden war.

Gleichzeitig sandte anf meinen Wunsch mein verebrter College Prof. Grünhagen in Königsberg mir in zwei Sendungen über 500 junge R. fuscae aus der dortigen Gegend am 21. Juli.

Ich bestimmte den Procentgehalt der jungen Männchen und fand 46,7. Die in Bonn gezüchteten Fröschehen von Königsberger Ursprung hatten $48,5 \%$ für das männliche Geschlecht ergeben. Bei den aus Königsberg erhaltenen jungen Fröschchen, die sich in der freien Natur entwickelt hatten, wurde eine Beobachtung gemacht, die nicht unwichtig ist. Ich erhielt die Fröschehen in zwei Sendungen. Von denen der ersten Sendung war die Hälfte durch die Hitze a. s. w. gestorben und die Ueberlebenden - es waren 167 Stück - ergaben 47,2\% Männchen, also fast genau so viel als die zweite Sendung, bei der der Tod keine Auslese gehalten.

Nehme ich zu den an den Utrechter und Königsberger Fröschchen erhaltenen Resultaten hinzu, dass im vorigen Jahre die von mir künstlich gezüchteten Fröschchen Bonner Abstammung einen $\%$-gehalt von 35,7 für das männliche Geschlecht ergaben, der fast identisch mit dem fuir die in der freien Natur entstandenen Thiere, für welche $36,3 \%$ ermittelt worden war, so erkennt man, dass die nach Race verschiedene Natur der Eltern, die Ei und Samen in sich entwickeln, maassgebend ist für den Character der Entwicklung der Geschlechtsorgane in den jungen Geschöpfen nach der Befruchtung, und dass eine Reihe der abnormsten Einflüsse, welche ein Ei nach der Befruchtung treffen, Nichts vermögen zur Aenderung der angestammten Geschlechtsverhältnisse. Für mich ist desshalb die Hoffnung, dureh irgend welche Einwirkungen das Geschlecht eines befruchteten Eies bestimmen zu können, eine minimale, ja es erscheint kaum glaublich, dass irgend welche Einwirkungen, die vor der Befruchtung das reife Ei und den reifen Samen treffen, einen Einfluss auf das Geschlecht auszuiiben vermögen.

Unsere Ergebnisse sind in guter Uebereinstimmung mit der wichtigen Thatsache, dass bei den Bienen alle Eier, die von dem Samen der Drohnen befruchtet waren, sich ausnahmslos zu Weibchen entwickeln. Hier zeigt uns die Natur, dass wenn ein be- 
stimmter Same und ein bestimmtes Ei auf einander wirken, ein ganz bestimmtes Geschlecht mit dem Act der Zengung gegeben ist. Bei den Bienen tritt die wunderbare Thatsache auf, die ich nirgends hinreichend hervorgehoben finde, dass die eigentlichen Männchen, d. h. die Drohnen, keine gewöhnlichen Männchen sind, sondern halbwerthige, weil sie Hoden haben, denen nur die halbe Potenz innewohnt, und desshalb keine Männchen zu zengen vermögen. Die andere Hälfte der Potenz liegt im Bienenweibchen. Es wird freilich behauptet, dass die Eier, welche sich zu Männchen entwickeln, gar nicht befruchtet waren. Das würde heissen, dass bei den Bienen alle Männchen ohne Befruchtung entstehen. Es ist nicht za vergessen, dass die Spermatozoen nicht immer nothwendig Flimmerzellen zu sein brauchen und demnach der Forschung bisher entgangen sein können diejenigen in der sogenannten Bienenkönigin producirten Spermatozoen, durch deren Einwirkung auf das Ei männliche Individuen entstehen. Diese Spermatozoen, die Männchen zeugenden, könnten ganz anders und unscheinbarer aussehen, als die Weibchen zeugenden der Drohnen. Erst wenn ein gelegtes $\mathrm{Ei}$, das angeblich unbefruchtet ist und sich zum Männchen entwickelt, durch künstliche nachträgliche Befruchtung mit Drohnensamen zur Entwicklung des weiblichen Geschlechts bestimmt werden kann, würde die Parthenogenese der Bienen bewiesen sein.

Es bleibt uns nun schliesslich das grosse Räthsel unserer Untersuchungen noch zu lösen übrig. Das von Born und mir beobachtete fast vollkommene Verschwinden der männlichen Individuen, wie z. B. bei den holländischen (resp. Utrechter) Fröschen ist an sich ein Absurdum - und zwar aus folgenden Grïnden. Im Anfange des März paaren sich die braunen Grasfrösche (R. fusca Roesel, R. platyrrhinus Streenstrup) und Wochen lang sitzt dasselbe Männchen auf demselben Weibchen, bis endlich alle Eier meist in Zeit von wenigen Minuten plötzlich entleert und befruchtet werden. Ohne Beihülfe des Männchens kann das Weibchen überhaupt nicht laichen. Selbst wenn man zu der Zeit, wo alle Eier bereits im Uterus des Weibchens liegen und unmittelbar vor der Entleerung die Männchen von den Weibchen sondert, was ich gethan habe, findet man, dass die meisten Weibchen ihre Eier nicht ausstossen können. Die Eier sterben im Uterus ab und auch die Weibchen gehen zu Grunde. Das Froschmännchen ist 
also ein wirklicher Geburtshelfer und die Geburtshelferkröte ist nur ein specieller Fall für ein unter den Batrachiern sehr allgemein verbreitetes merkwitrdiges Gesetz. Schon Valisneri berichtet, dass Froschweibchen obne Männchen keine Eier legen, wohl aber lege das Weibchen auch ohne Männchen Eier, wenn erst nach längerer Umarmung, nachdem die Eier in den Uterus gelangt sind, das Männchen gewaltsam entfernt wird. Spallanzani $^{1}$ ) berichtet, dass bei der stinkenden Erdkröte die Eier im Eierstock bleiben, wenn das Weibchen vom Männchen entfernt gehalten wird. Ich glaube, dass es bei den meisten Batrachiern sich ebenso erhält. Denn ich habe wiederloolt beobachtet, dass auch bei Rana esculenta dasselbe Männchen anf demselben Weibchen 4 Wochen lang in brïnstiger Umarmung sass, obwohl mehr Weibehen vorhanden waren. Bei dem brannen Grasfrosch findet ferner die Eigenthümlichkeit statt, dass fast alle Thiere derselben Gegend an fast demselben Tage laichen. So laichten in diesem Jahre 1882 alle R. fuscae am 19. und 20. März. Es ist wahr, es kommen einige Vorläufer and einige Nachzügler vor; ihre Zahl verschwindet aber total gegen die Zahl derjenigen, welche den allgemeinen Termin der Absetzung des Laichs innehalten. Wenn man deshalb die Orte untersucht, wo in den Tümpeln die zahllosen Laichklumpen des braunen Grasfrosches liegen, wird man die Larven fast alle in nahe demselben Stadium der Entwicklung antreffen. - Weil also ein Männchen des braunen Grasfrosehes bei einem einzigen Weibchen ununterbrochenen Dienst hat von circa mehreren Wochen, so ist es klar, dass genau so viele Männchen als Weibchen da sein müssen, wenn die Eier aller Weibchen befruchtet werden sollen. Ein Männchen kann nicht, wie bei den polygamen Thieren, z. B. den Hühnern, die Eier vieler Weibchen befruchten. Wenn also Spallanzani ${ }^{2}$ ) berichtet, dass Männchen von Kröten und Fröschen mehre Weibchen befruchten könnten, so kann es sich nur um ganz besondere Fälle oder eigenthümliche Ausnahmen handeln. Denkbar ist dies als Gesetz für solche Batrachier, deren Weibchen auch ohne brïnstige Umarmung des Männchens Eier legen, was nach Spallanzani ${ }^{3}$ ) bei Bufo igneus vorkommen soll. Das ist bei dem braunen Grasfrosch ausgeschlossen. Die

1) Spallanzani, a. a. O. p. 47.

2) Spallanzani, a. a. O. p. 34 .

3) Spallanzani, a. a. O. p. 87. 
Natur zeigt nun aber überall, dass sie das Weibliche für wichtiger als das Männliche, das Ei für viel werthroller als den Samen betrachtet. Denn Millionen von Spermatozoen gehen im natiirlichen Lauf der Dinge zu Grunde: jedes Ei wird aber in der Natur der Regel nach befruchtet. Bedingungen schaffen, durch welche viele Eier zum Untergang bestimmt sind, weil es an dem befruchtenden Samen fehlt, wäre deshalb ein Absurdum. Da aber die Regel der Natur das Princip der Zweckmässigkeit ist, so fragt es sich, wie das Beobachtete mit diesem in Einklang gebracht werden kann. Nach dem von mir aufgestellten Princip der teleologischen Mechanik, das ich in der Folge vorschlage zu nemnen: das allgemeine Princip der Selbststeuerung der lebendigen Natur, muss gefolgert werden, dass ein plötzliches ungeheures Ueberwiegen der weiblichen Geburten unter den hier obwaltenden Bedingungen nur Sinn hat, wenn gleichzeitig unter den alten Thieren ein ebenso ungeheures Ueberwiegen des männlichen Geschlechts zu constatiren ist. Man sieht, dass sehr viele Weibchen nach dem Laichgeschäft sterben, und es wäre denkbar, dass durch irgend welche besondere Schädlichkeit in Holland ein grosses Sterben der Weibehen in den letzten Jahren stattgefunden hätte. Die Folge würde die sein, dass viele Männchen im vorigen Jahre ihre Geschlechtsverrichtungen nicht hätten ausuiben können, viele also in diesem Jahre nach einer 2jährigen Ruhepause die Eier der noch restirenden Weibchen befruchtet haben wiirden. Man mïsste dann annehmen, dass der Same dieser so lange abstinent gewesenen Männchen wesentlich nur Weibchen zeuge.

Ist diese Betrachtung richtig, dann war die nothwendige Folge:

Unter den alten Fröschen von Utrecht müssen die Männchen bedeutend an Zahl die Weibchen iiberwiegen, in Bonn muss ein Gleiches aber in geringerem Grade stattfinden, und in Königsberg würden wir gleiche Zahl beider Geschlechter unter den alten Fröschen erwarten.

Abermals bezog ich in diesem Jahr durch die gitige Vermittlung meines verehrten Collegen Engelmann in Utrecht 297 alte frisch gefangene Frösehe, die 145 Männchen enthielten, also $48,8 \%$.

Unter diesen 297 waren 44 Stïck halbwüchsige. Wenn ich diese abziehe, so bleiben 253 Stück mit 120 Männchen oder $47,5 \%$ Männchen. 
Ueb. die d. Geschlecht best. Ursachen u. d. Geschlechtsverhältn. d. Frösche. 29

Das Verhältniss der Geschlechter unter den alten Fröschen in Utrecht ist also sehr nahe das Gleiche.

Ferner erhielt ich am 25. Juli durch die gitige Vermittlung meines verehrten Collegen Grün hag en aus Königsberg zwei Körbe von alten frisch eingefangenen $R$. fuscae. Der erste Korb enthielt 127 Stück mit 59 Männchen, entsprechend $46,5 \%$; der zweite Korb 183 Stück mit 96 Männchen, entsprechend 52,4\%. Ich hatte also $127+183=310$ mit 155 Männchen entsprechend: $50,0 \%$.

Sehr lehrreich ist hier, dass die auf Grund ron 127 Stück ausgeführte Bestimmung des Procentgehaltes immer noch eine $\mathrm{Ab}$ weichung von $3,5 \%$ gibt und die auf Grund von 183 Stiick ausgeführte Bestimmung immer noch einen Fehler von 2,4\%, woraus man sieht, dass erst circa 300 bis 400 Bestimmungen annähernd verlässliche Mittelwerthe geben. Das mögen besonders die Zoo-, logen beachten, die an einem Tümpel stehend, unter 50 bis 60 Thieren, die sie sehen, bald mehr Weibchen, bald mehr Männchen wahrnehmen, und dann auf ein allgemeines Ueberwiegen des einen Geschlechtes glauben schliessen zu dürfen.

Endlich habe ich das Verhältniss der Geschlechter bei den alten frisch gefangenen Grasfröschen Bonn's bestimmt.

Diese Thiere, von denen ich einen beträchtlichen Theil der guitigen Vermittlung des Herrn Dr. Adolf von Griesheim verdanke, waren im weiten Umkreise des Dottendorfer Lochs, des grossen Laichplatzes, in dicsem Juli und August frisch gefangen.

281 Thiere entbielten 139 Männchen, d. b. 49,4\%.

Addire ich die 64 Stück alter Frösche, welche Herr von Griesheim voriges Jahr fing und unter denen durch Zufall die grosse Zahl von 37 Männchen sich befand, so ergeben sich: 345 alte Thiere mit 176 Männchen oder $51,0 \%$.

Es ist also klar: Auch in Bonn zeigt sich kein Ueberwiegen des männlichen Geschlechts. Denn das Plus von 1 Procent liegt noch ganz innerhalb des Beobachtungsfehlers.

Bemerken will ich noch, dass unter den 345 „alten Fröschen" circa der dritte Theil aus Thieren im dritten Lebensjahre bestand, was ja der Sache keinen Abbruch thut. Ich wünschte diese halbwiichsigen erst im folgenden Jahre zengenden Individuen von den wirklich alten, die bereits gezengt hatten, zu sondern, musste aber davon abstehen, weil es zwar möglich ist, die im dritten Lebensjabre stehenden Weibchen, nicht aber die gleichaltrigen jungen 
Männchen mit Sicherheit zu diagnostiren. Jene besitzen zart seegrüne, nicht oder wenig schwarz pigmentirte Eierstöcke: einzelne der männlichen Individuen von gleicher Körpergrösse haben aber im Juli und Angust Hoden von wenigen Millimetern Länge, andere von über $1 \mathrm{Cm}$, und sind vielleicht alte Männchen von kleiner Statur.

Da mir nun das Verhältniss der Geschlechter bei den alten Fröschen Bonn's für das Jahr 1882 genal bekannt war, so schien es mir sehr wichtig zu untersuchen, ob unter den jungen diesjährigen braunen Grasfröschen die Zahl der Mänuchen wieder eine so geringe wie im vorigen Jahre 1881 wäre. Ich fing deshalb selbst am 29. Juli auf einem neben dem Dottendorfer Loch gelegenen halb durch Regen ïberschwemmten Kleefelde 228 diesjährige seit 2 Monaten verwandelte, in der freien Natur entstandene, braune Grasfröschchen und constatirte 81 Männchen oder $\mathbf{3 5 , 5} \%$. Im vorigen Jahre hatte ich mit Herrn Adolf von Griesheim $36,3 \%$ d. h. sehr nahe dieselbe Zahl gefunden. Dass die von mir jetzt untersuchten Thierchen diesjährige waren, folgte aus der Grösse, die im Mittel $17 \mathrm{Mm}$ betrug und diesen Werth nur in wenigen Exemplaren um 1 bis $3 \mathrm{Mm}$ ib berstieg. Diese Länge ist gemessen von der Spitze der Schnanze bis zum After. Ich sagte, die Thiere seien seit circa 2 Monaten verwandelt, weil ich am 6 . Juni selbst am Dottendorfer Loch war und sehr viele junge braune Grasfrösche mit fast ganz geschwundenem Schwanze unter vielen mit noch vorhandenem Stummel wahrgenommen hatte.

Es bleibt mir eine Bemerkung zunächst noch zu machen über die Geschlechtsbestimmung bei den alten Fröschen. Ich tödtete sie, indem ich ein wenig Aether in das Gefäss goss, in dem sie sassen und öffnete das Abdomen.

Ausser der Laichzeit sind die secundären äusseren Verschiedenheiten beider Geschlechter unzuverlässige Kennzeichen. Nach Leydig ${ }^{1}$ ) haben die Männchen ausser der Laichzeit grawe Daumenschwiele. Ich habe sehr viele Männchen mit nicht pigmentirtem Daumenballen gefunden und Weibehen, bei denen er graner als bei vielen Männchen erschien. Roesel von Rosenhof ${ }^{2}$ ) gibt

1) Leydig, Die anuren Batrachier der deatschen Fauna. 1877. p. 117.

2) J.A. Roesel von Rosen h of, Naturgeschichte der Frösche Deutschlands. Neue Auflage von 1815. Vorrede von 1753. p. 4. 
an und Autoritäten auf diesem Gebiet bestätigen, dass der Bauch des Weibchens gelblich mit rothbraunen Flecken gezeichnet sei, während der des Männchens grauweiss, wenig oder gar nicht gefleckt erscheine. Nicht selten sind mir mächtige Männchen, deren ich Eines zum Beweise für Jedermann in Spiritus aufbewahre, vorgekommen, deren gelblicher Bauch und Brust mit zahlreichen rothen Flecken ganz übersäet war. Die Stärke des Vorderarms ist auch kein ausreichend sicheres Merkmal und die Nachweisung der Stimmblase bei den Männchen zu unständlich.

Das Resultat dieser Untersuchung ist, dass bei den alten braunen Grasfröschen in Utrecht, Königsberg und Bonn Männchen und Weibchen in gleicher Zahl vertreten sind, während bei den jungen überall ein bald grösseres bald geringeres Zurücktreten des männlichen Geschlechts bemerkt wird. Der Procentgehalt für das männliche Geschlecht bei den Jungen scheint von Null bis $50 \%$ zu schwanken, $50 \%$ aber $\mathrm{n}$ i e zu übersteigen.

Ist es nun denkbar, dass in der Jugend die Mortalität des weiblichen Geschlechts grösser als die des männlichen sei, sodass schliesslich Gleichheit der Zahl der Männchen und Weibchen resultirt? Das ist deshalb anzunchmen nicht möglich, weil dann in Königsberg, wo schon bei den jungen fast gleiche Zahl beider Geschlechter vorhanden ist, schliesslich bei den Alten nicht mehr Gleichheit der Zahl der Männchen und Weibchen gefunden werden könnte, und weil bei den Utrechter Fröschen Herstellung gleicher Procentzahl für beide Geschlechter ein ganz colossales Absterben der Weibchen nothwendig machen würde. Es bleibt demnach keine andere Möglichkeit als folgende, die ich schon im vorigen Jahre fortwährend im Auge hatte, aber zu erweisen nicht vermochte:

Bei den jungen Fröschen gibt es dreierlei Arten von Thieren: Männchen, Weibchen, Hermaphroditen. Im Laufe der Entwicklung verwandeln sich die Hermaphroditen in definitive Weibehen oder Männchen. Wenn nun bei einem Hermaphröditen, der später ein Männchen wird, das Eierstockgewebe sehr stark entwickelt ist, so nimmt die Geschlechtsdrüse in ihrem äusseren Habitus, und natiirlich auch bei mikroskopischer Untersuchung ganz den Character eines Eierstocks an. Das Thier ist aber trotzdem später ein Männchen. Da also schon diejenigen Hermaphroditen, welche später sich in Männchen verwandeln, für weiblich bei der Untersuchung angesprochen werden, ist es für die Hermaphroditen, aus 
denen später wirklich Weibehen entstehen, natïrlich auch der Fall. Je nach dem Grade der Entwicklung des Hermaphroditismus scheint dann das männliche Geschlecht bald mehr bald weniger znrïckgedrängt.

Wie lässt sich dies erweisen? - Als ich die Born'sche Arbeit von dem Verschwinden des männlichen Geschlechts bei den von ihm gezüchteten braunen Grasfröschchen gelesen hatte, war meine erste Meinung, dass er durch Hermaphroditismus getäuscht worden sei. Ich habe meine Betrachtungen dariber ja im vorigen Jahre (Dies. Archiv XXVI. pag. 244) weitläufig auseinander gesetzt. Ich untersuchte deshalb oft die recht characteristisch sich als Hoden manifestirenden Geschlechtsdrüsen meiner jungen Fröschchen, sah überall nur Hodengewebe, nirgends einen Graaf'schen Follikel. Ich überzeugte mich, dass die Procentzahl der Männchen nicht zunahm, wenn ich meine Thiere in meinem Garten noch einen Monat weiter zuichtete. Ja als ich im Herbst (September) die jungen Fröschchen von 1881 untersuchte (Dies. Arehiv XXVI. pag. 240), fand ich abermals keine Steigerung der Procentzahl für die Männchen.

Heute nach den mir vorliegenden Ergebnissen bleibt also nur die Möglichkeit, dass sich die Umwandlung der Zwitterdriise in einen Hoden sehr langsam, resp. im zweiten und dritten Lebensjahre des Thieres vollzieht durch allmählich eintrefende Resorption des Ovarialgewebes oder dass das letztere bleibt und nur vom Hodengewebe uiberwuchert wird, sodass bei der wachsenden Grösse des Thieres dann die Gestalt der Hoden ans dem scheinbaren Eierstock sich differenzirt. Wenn ein allmähliches Schwinden des Ovarialgewebes durch Resorption eintrete, so sollte man meinen, dass doch im Herbste schon eine Aenderung der Procentzahl der Männchen sich offenbaren musste, da ja im ersten Sommer die Geschlechtsorgane der kleinen Fröschchen fortwährend sehr mächtig wachsen. Bleibt aber das Ovarialgewebe bestehen, und ist der Hoden später wirklich ein Hodeneierstock, so setzt dies voraus, dass das den vielen Beobachtern, welche sich mit der mikroskopischen Anatomie der Sexualorgane der Batrachier beschäftigt baben, entgangen ist, was mir unwahrscheinlich dünkte.

Gleichwohl musste ich nun die letztere Möglichkeit priifen. Da die Entwicklung des hypothetischen Hermaphroditismus bei den holländischen Fröschen so mächtig ist, und um der Möglichkeit 
Rechnung zu tragen, dass doch sehr langsam der ganze Theil des Ovarialgewebes der Hoden resorbirt wird, und bei ganz ansgewachsenen Männchen nur noch in Spuren vorhanden ist, wählte ich halbwiichsige, etwa $5 \mathrm{Cm}$ lange, also im dritten Lebensjahre befindliche, holländische Männchen. In diesem Alter ist der Eierstock gelappt, von gelblich grüner, der Hode von gelblich weisser Farbe und eharakteristischer Gestalt. Ein Irrthum im Gesehlecht ist unmöglich. Die Hoden härtete ich in einer Mischung von 2 Volumina Alkobol und 1 Volumen Wasser. Sie bleiben mehre Tage brauchbar für die Untersuchung. Dann schnitt ich mit dem Rasirmesser diunne Scheibchen vom Anfang bis zum Ende senkrecht auf die Axe des Hoden und brachte diese Scheibchen für circa 12-24 Stunden in eine Lösung von 1\% $\%$ iger Ueberosmiumsäure.

Als ich nun so die 6 Hoden von 3 Thieren mit scharfen Nadeln vollständig zerzupft und durchuntersucht hatte, fand ich nicht die Spur eines Graaf'schen Follikels. Bei dem vierten Froschmännchen war ich aber gliicklicher. Ich entdeckte plötzlich einen grossen Graaf'schen Follikel von 0,15 Mm, wie man ihn nur wünschen kann: Kernhaltige Hïlle, zarten sehr fein granulirten Dotter, ungeheures scharf und doppelt conturirtes Keimbläschen von $0,08 \mathrm{Mm}$ mit den bekannten zahlreichen, das Licht stark brechenden Keimflecken. Noch gliieklicher war ich bei dem fünften Froschmännchen. Jede Lamelle senkrecht auf die Axe des Hoden genommen, lieferte mir mehre prachtvolle Follikel von verschiedener Grösse. Einmal zählte ich 11 Follikel auf demselben Objectglas. Diese Hoden enthielten das Eierstocksgewebe nicht blos in dem vorderen Theil, sondern auch in dem hinteren; der vordere Abschnitt der Hoden schien aber reicher an Eierstocksgewebe als der hintere. Der rechte Eierstock verhielt sich wie der linke. Darauf hatte ich bei der Untersuchung der Hoden mehrerer Männchen wieder keinen Erfolg, fand aber dann abermals einen Graaf'schen grossen Follikel in einem Hoden. Ich hätte gern den Grad der Verbreitung des Hermaphroditismus genauer bestimmt. Es ist aber eine unglaubliche Geduldprobe, den ganzen Tag von Morgens bis Abends Zerzupfungspraeparate zu machen, um schliesslich am Ende des Tages 2 Männchen, i. e. 4 Hoden untersucht zu haben, in denen man vielleicht nicht einen Graaf'schen Follikel gefunden hat. Dabei ist die Zerzupfung der Präparate unter der Lupe in einem Tropfen Ueberosmiumsäure wegen deren giftiger ätzender Dämpfe sehr 
angr eifend für die Respirationsorgane; mein empfohlenes Verfahren aber doch zur schnellen Orientirung über das ganze Organ sehr zweckmässig. Der Hode zerfällt dann ungemein leicht in zahllose feine Partikeln, wie sie für die mikroskopische Untersuchung nöthig sind.

Es ist also sicher der scheinbare Hode des braunen Grasfrosches eine Zwitterdrüse und die Menge des Eierstocksgewebes sehr variabel und irregulär, sodass möglicherweise manche Hoden kein mit unseren gegenwärtigen Mitteln nachweisbares Eierstocksgewebe enthalten, wenn es auch in ganz rudimentärer Form vorhanden sein mag. Solche Froschmännchen verhalten sich also dann wie die ächten Männchen anderer Wirbelthiere und bei ihnen tritt die charakteristische Form des Hoden schon sehr früh, $\mathbf{d} . \mathbf{h}$. in dem ersten Monat nach der Metamorphose ein.

Da irregulärer und rudimentärer Hermaphroditismus die wahre Erklärung des scheinbaren Ueberwiegens des weiblichen Geschlechts bei den jungen braunen Grasfröschen ist, versteht man auch noch folgende von mir beobachtete Thatsache.

So oft ich ein Aquarium zu untersuchen hatte, in dem männliches und weibliches Geschlecht gleichstark vertreten war, wie z. B. bei den Königsberger Fröschehen, machte mir die Diagnose des Geschlechts gar keine Mühe. Ein Blick auf die Drïse und die Diagnose war gestellt; fast niemals wurde das Mikroskop zu Rathe gezogen. Mit Einem Worte: die Organe waren entweder typische Hoden oder typische Eierstöcke, und solche Drüsen, bei denen man zweifelhaft ist, kamen fast gar nicht vor.

Ganz im Gegentheil machte mir die Diagnose der Utrechter kleinen Frösehehen die allergrösste Mühe. So ausserordentlich zahlreich waren die Organe, deren Diagnose zweifelhaft war. Dabei zeigten sich gerade die Utrechter aus der Natur bezogenen jungen Fröschchen viel besser und kräftiger genährt als die Königsberger.

Mit einem Worte: ich kann es als ein ganz sicheres Resultat meiner zahlreichen nach Tausenden sich beziffernden Diagnosen bezeichnen: Je grösser die Procentzahl der Weibchen zu sein schien, desto zahlreicher waren die Drüsen, bei denen die Diagnose zweifelhaft war: Uebergangsformen von Hode zu Eierstock.

Glïcklicherweise hatte ich alle bis dahin auf ihre Geschlechtsverhältnisse untersuchten Fröschchen in Spiritus aufbewahrt, mit 
Ausnahme der zur mikroskopischen Zergliederung verwandten und versuchte demnach schliesslich bei den Bonner und Utrechter Präparaten nochmals die Diagnose $\mathrm{zu}$ stellen, da ich also jetzt fast sicher wusste, dass beide Geschlechter in gleicher Zahl vertreten seien. Ich betrachtete deshalb die hermaphroditischen Uebergangsformen genauer von diesem Gesichtspunkte aus und verwarf jede Form, bei der mir der geringste Zweifel aufstieg. Als zweifelhaft betrachtete ich solche scheinbaren Eierstöcke, welche, trotzdem sie um ein Vielfaches an Volum die ächten Hoden und selbst die Hälfte der Niere an Länge übertrafen, doch eine glatte Oberfläche, mehr ode weniger walzenförmige und etwas abgeplattete Gestalt, sowie in Alkohol ein weisslich trübes Ansehen darboten. Die ächten Eierstöcke haben meist, wenn ihre Entwicklung einigermassen vorgeschritten, Einschnürungen, den ersten Anfang der späteren Lappenbildung und sind ganz durchsetzt von kleinen, sehr zahlreichen runden wasserklaren Perlen, wenn man die Drüse unter der Lupe in Alkohol betrachtet.

Als ich nun die Bonner jungen Fröschchen von diesem Jahre, welche ich am 29. Juli gefangen hatte, nach Verwerfung aller zweifelhaften bestimmte, ergaben sich 45,3\% Männchen. Diese Bestimmung geschah an 179 Fröschchen. Dazu gehören 49 zweifelhafte, die übrigens ganz weiblichen Character haben.

Nimmt man an, dass von diesen 49 zweifelhaften Hermaphroditen sich $2 / 3$ später in Männchen verwandelt haben würden und $1 / 3$ wirklich weiblich ist, so ergibt sich, dass die untersuchten 228 Thierchen 114 Männchen enthielten oder $50 \%$.

Ich habe eine ähnliche Nachuntersuchung mit den in Alcohol conservirten Fröschchen aus Utrecht vorgenommen, wobei sich ergab, dass selbst nach Ausschalten der zweifelhaften Exemplare immer noch ein sebr bedeutendes Ueberwiegen der Weibchen vorhanden zu sein scheint. Klar ist also, dass bei vielen Hermaphroditen, die später Männchen werden, in der ersten Zeit des Lebens des jungen Fröschchens nach der Metamorphose eine so üppige Entwicklung des Eierstockgewebes eintritt, dass die Drüse nach Aussen sowohl in Gestalt und Grösse ganz das charakteristische Ansehen eines Ovariums annimmt, was sie ja auch - wenn auch nur theilweise - ist.

Die von mir beigebrachte Beweisfuihrung für den Satz, dass auch bei jungen braunen Grasfröschen beide Geschlechter in glei- 
cher Zahl vertreten sind, das Ueberwiegen des weiblichen Geschlechts ein nur scheinbares ist, stützt sich auf die Annahme, dass, weil bei den alten Thieren im Jahre 1882 in Utrecht, Königsberg und Bonn Männchen und Weibchen in gleicher Zahl auftreten, es unter allen Umständen so sein werde. Diese Verallgemeinerung wird vielleicht manchem Leser als zu weitgehend erscheinen, und ich war deshalb bemiuht, meinen Beweis zu ergänzen.

Die schlagendste Ergänzung wïrden die dem Dottendorfer Loch entstammenden im zweiten Jahre stehenden Frösche liefern, deren Procentgehalt an Männchen wir im vorigen Jahre bestimmten. Es fragte sich nur, woran die im zweiten Lebensjahre stehenden zu erkennen und wo sie, da sie sich allmählig von ihrer Brutstätte über das Land verbreiten, zu finden seien.

Bei den von mir selbst ausgeführten Excursionen sowie bei den von bestimmten Oertlichkeiten mir eingelieferten braunen Grasfröschen zeigte sich die eigenthümliche Erscheinung, dass fast an jeder bestimmten Oertlichkeit, wo R. fusca iiberhaupt vorkommt, bald mehr bald weniger alte Individuen $\mathrm{zu}$ finden sind, während die jüngeren Exemplare fast alle ausnahmslos von annähernd derselben Grösse erscheinen.

Auf dem Felde, wo ich am 29. Juli 228 junge diesjährige Ranae fuscae fing, war nicht ein einziger vorjähriger Frosch zu finden, keiner, der also 25 bis $37 \mathrm{Mm}$ lang gewesen wäre. Auf denjenigen Wiesen, wo im nassen Grase neben den alten Thieren, halbwüchsige von ca. $50 \mathrm{Mm}$ Körperlänge in grösserer Zahl sich herumtummelten, fand sich eine juingere Generation absolut nicht vor. Wie ans dem weiter oben Gesagten hervorgeht, traf ich Anfangs Angust und Ende Juli auf einem grossen Kleefelde die ganze diesjährige Brut des Dottendorfer Lochs noch zusammen. Man sieht also, dass sich die einem Laichplatz entstammende Generation eines Jahres mehrere Jahre herdenartig zusammenhält and so allmählig über die Wiesen und Felder zieht. Ich suchte demgemäss nach dem Standort der vorjährigen Generation und fand ihn auf einigen benachbarten sehr feuchten Wiesen zwischen Dottendorf and Friesdorf, die ca. 20 Minuten vom Dottendorfer Loch entfernt liegen.

Es handelt sich nun um die Diagnose des Alters der jungen braunen Grasfrösche. Das Beste, was ich über diese Frage in der 
Literatur finden konnte, sind die Angaben von J. A. Roesel ron Rosenhof.

Er zeichnet colorirt und nicht colorirt den im zweiten, dritten und vierten Lebensjahre stehenden braunen Grasfrosch in Lebensgrösse $\mathbf{a} \mathbf{b}^{\mathbf{1}}$ ) und stellt die Diagnose nach der Körperlänge.

Der Frosch hat im Juli des zweiten Jabres nach Roesel eine Rumpflänge von Schnauzenspitze bis After von im Mittel $30 \mathrm{Mm}$; im dritten Jahre misst er zur selben Zeit im Mittel $45 \mathrm{Mm}$. Roesel gibt nicht an, welche Beweise er für seine Behauptung beizubringen vermag, und ich will sie deshalb anführen, da ioh mit Roesel im Wesentlichen iibereinstimme.

Wenn ich die kleinsten Fröschchen Ende Jali auf ihre Körperlänge untersuchte, so schwankte sie von ca. 13 bis $18 \mathrm{Mm}$.

Exemplare von 18 bis $22 \mathrm{~mm}$. finden sich za dieser Zeit entweder gar nicht oder in spärlicher Zahl.

Wohl aber zeigt sich dann wieder eine Generation in grosser Zahl, deren Körpergrösse von 22 bis $37 \mathrm{Mm}$ schwankt und im Mittel $3 \mathrm{Cm}$ beträgt. Exemplare von 37 bis $45 \mathrm{Mm}$ sind zu dieser Zeit entweder gar nicht oder doch nur in ganz seltenen Fällen vertreten.

Dann kommt wieder eine Generation in grösserer Zahl, die im Juli 45 bis $55 \mathrm{Mm}$ misst.

Diese Sprünge in der Körperlänge denten unverkennbar darauf hin, dass die Generation, die im Juli im Mittel $15 \mathrm{Mm}$ langen Rumpf aufweist, in dem ersten Jahr, die, welche im Mittel $30 \mathrm{Mm}$ hat, in dem zweiten und die, welche $50 \mathrm{Mm}$, in dem dritten L $\theta$ bensjahre sich befindet. Im Mittel nimmt also die Leibeslänge vom ersten zum zweiten Sommer um 15, vom zweiten zum dritten um 15 bis $20 \mathrm{Mm}$ zu.

Meine Zahlenangaben beziehen sich auf die Bonner Race, die mit Roesel's Angaben in Uebereinstimmung bleibt. Ich habe aber gesehen, und das muss hier beachtet werden, dass die diesjährigen jungen Ranae fuscae, deren Eltern aus einem Gebirgsee von Glarus in der Schweiz stammten, die Bonner gleichaltrigen an Körperlänge im Durehschnitt beträehtlich übertrafen. Auch die Eier der Weibchen aus Glarus waren viel dicker und die Quappen anfangs viel grösser als die anderen Heimathsorten entstammenden.

1) Roesel a. a. O. Taf. III. Fig. 36. 37. 38. 
Zur Diagnose der im zweiten Lebensjahre stehenden braunen Grasfrösche kann ich Roesel's Angabe noch durch eine sehr wesentliche Beobachtung weiter stiitzen. Ich hatte im vorigen Jahre die Bonner Fröschchen in einem Drahtgitterhäuschen im Freien weiter gezüchtet, wie ich seiner Zeit genaner beschrieben. Einige dieser Thierchen - es waren sieben Stück - hatten sich in Erdspalten, welche der Rasen des Drahthäuschens darbot, verkrochen, wo sie iiberwinterten, um im Frïhjahre wieder zum Vorschein zu kommen. Sie waren äusserst kräftig; weil sie im Rasen hinreichend Nahrung fanden. Die Rumpflänge der grössten dieser Fröschchen betrug $21 \mathrm{Mm}$ am 26. Juni 1882. Da nun, wie ich gesehen habe, die Thiere in der ganz freien Natur doch mächtiger werden und im Juli und August sehr stark wachsen und die Ende Juli und Anfangs August von mir angestellten Messungen die Länge der im zweiten Lebensjahre stehenden zu 22 bis $37 \mathrm{Mm}$ ergaben, so zweifle ich nicht an Roesel's Angabe.

Es kommt ein weiterer Grund hinzu. Wenn ich die Ovarien der von mir bis in das zweite Jahr gezüchteten Thiere untersuchte, zeigten sie sich in Weingeist betrachtet Ende Juni schneeweiss, geradeso wie die der ganz jungen und hatten hier und da auf der Oberfläche eine leichte Kräuselung. Genau so verhielten sich Ende Juli die in freier Natur erwachsenen im zweiten Lebensjahre stehenden Thiere. Erst im August zeigen einzelne Ovarien einen gelblichen Schein.

Ganz anders stellen sich die Ovarien der 45 bis $55 \mathrm{Mm}$ langen, d. h. im dritten Lebensjahre stehenden Frösche dar. Abgesehen von der stark gekräuselten Oberfläche und bedeutenderer Grösse sind sie in Alkohol betrachtet nicht mehr weiss, sondern zart seegrün und mit Spuren wie anch grösseren Mengen schwarzen Pigmentes durchsetzt. Der von Pigment ganz freie Eierstock ist deshalb bei sehr grossen, im zweiten Jahre stehenden Fröschchen, die ihrer Länge nach möglicherweise als dreijälrige verdächtig erscheinen, ein höchst werthvolles Mittel der Diagnose.

Von dieser im zweiten Lebensjahre stehenden Generation fing ich am 24. Juli, am 28. Juli und am 5. August eine Anzahl von 253 Stück, tödtete sie in Alkohol, öffnete das Abdomen und brachte sie in Alkohol zurück. Die Diagnose konnte mit blossem Auge mit Leichtigkeit ansgeführt werden. 100 Stück betrachtete ich zur besseren Orientirung mit der Lupe und 153 bestimmte ich 
ohne bewaffnetes Auge. Diese 253 im zweiten Jahre stehınden Fröschchen enthielten 124 Männchen oder $49,0 \%$. Beide Geschlechter absolut gleichmässig vertreten!

Als ich soweit gekommen war, suchte ich aus allen im zweiten Jahre stehenden Männchen diejenigen aus, welche die grössten Hoden hatten; denn die Schwankungen der Dimensionen dieses Organes sind unabhängig von der absoluten Körpergrösse des Thieres sehr beträchtlich.

Dann suchte ich ebenso alle zweifelhaften Geschlechtsdruisen aus den diesjährigen Fröschchen aus und zwar die kleinsten.

Beide Reihen legte ich nebeneinander und sah, wie ich erwartet hatte, dass alle zweifelhaften Drisen der diesjährigen Fröschchen, die fast alle sicher sich später in Hoden verwandeln, grösser, meist sehr viel grösser als die grössten definitiven Hoden der im zweiten Lebensjahre stehenden Thiere waren.

Daraus erwächst wohl keine ernsthafte Schwierigkeit. Wenn man sieht, wie die riesige $10 \mathrm{Cm}$ lange Quappe des Pelobates fuscus einfach durch Schrumpfung sich verwandelt in die kleine Knoblauchkröte, die an Volum von der Larve bedeutend übertroffen wird, wenn man beobachtet, wie der lange Ruderschwanz der Larve von $R$. fusea in 2 bis 3 Tagen bei warmem Wetter anter günstigen Verhältnissen bis zu einem minimalen Stummelchen resorbirt wird, so hat es keinerlei Schwierigkeit sich vorzustellen, wie in ähnlicher Weise eine grössere hermaphroditische Geschlechtsdriuse sich in einen kleineren Hoden umbildet. Freilich aber spricht dies sehr dafür, dass doch ein grosser Theil des Eierstocksgewebes der hermaphroditischen Drüse bei dieser Metamorphose versehwindet.

Endlich aber möehte ich noch einmal besonders hervorheben, dass die Stärke in der Entwicklung des Hermaphroditismus bei Rana fusca von der Race abhängt, wie meine Züchtungsversuche mit den Königsberger, Utrechter, Bonner Fröschen bezeugen. Alle anderen Einflïsse, die nach der Befruchtung die Eier treffen, sind ohne Belang. Denn die von mir künstlich gezüchteten Fröschehen von Utrechter Abstammung waren wegen zu spärlichen Futters ganz kleine verkimmerte Wesen gegen die vollsaftigen, gut ernährten Thierchen, die in der freien Natur in Utrecht aufgewachsen waren. Die Entwicklung des Hermaphroditismus war aber ganz gleich in beiden Fällen. 
Ebenso gilt es für Königsberg und für Bonn, wenn man unsere Versuche des vorigen Jahres in Betracht zieht.

$\mathrm{Zu}$ Versuchen iiber Geschlechtsursachen können also nur solche Raçen, resp. Varietäten des braunen Grasfrosches gebraucht werden, die wie die Königsberger fast keinen irregularen Hermaphroditismus aufweisen.

\section{Ueber die parthenogenetische Furchung der Eier der Amphibien.}

Von

E. Pflüger.

Nicht wenigen Forsehern der neueren Zeit scheint das grosse Geheimniss der Zeugung dadurch seiner Lösung wesentlich näher geriickt, dass die Eier einiger Thiere angeblich auch ohne Befruchtung sich entwickeln und die Eier Vieler wenigstens die Entwickelung anfangen, der Same also den Ablauf der Processe nur ein wenig zn unterstützen scheint.

Die spontane oder parthenogenetische, d. h. ohne Befruchtung eintretende Furchung der Eier wird für viele Thiere und auch für die Batrachier von hochangesehenen Forschern behanptet. Da ich über diesen Punkt volle Gewissheit haben musste für meine Versuche über Bastardzengung, untersuchte ich den Gegenstand genauer. Ich will zuerst diejenigen Thatsachen darlegen, deren Beachtung bei den Forschungen jener Gelehrten vermisst wird.

Spallanzani ${ }^{1}$ ) zeigte, dass 3 Gran - also ca. 4-6 Tropfen Same vom Frosch gelöst in $1 / 2$ Liter Wasser genügten, um alle Eier von 50 Froschweibchen, d. h. sehr viele Tausende, zu befruchten. Das Wasser war nachher noch immer fähig, nene Eier zu beleben. Wenn Spallanzani 3 Gran Same, also einige Tropfen in 22 Pfund Wasser vertheilte, so zeigte dieses Wasser noch immer befruch-

1) Spallanzani, Versuche über die Erzeugung der Thiere und Pflanzen. Deutsch. 1786. p. 188. 